\title{
Integrating presumptive and confirmatory semen tests into DNA profiling of sexual assault evidence: a Philippine example
}

\author{
Jae Joseph Russell B. Rodriguez ${ }^{1,2}$ (D), Gayvelline C. Calacal ${ }^{1}$, Rita P. Laude ${ }^{2}$ and Maria Corazon A. De Ungria ${ }^{1 *}$ (D)
}

\begin{abstract}
Background: In sexual assault casework, the detection of semen on a sample supports an allegation of sexual contact and indicates the presence of DNA from a male source. Ideally, techniques employed should demonstrate high sensitivity and specificity and should be compatible with standard DNA typing procedures. To contribute recommendations for routine DNA tests of sexual assault cases in the Philippines, we evaluated the RSID ${ }^{T M}$-Semen, an immunochromatographic test for human semenogelin ( $\mathrm{Sg}$ ), in parallel with the alternate light source (ALS) method using Mini BLUMAXX' ${ }^{\text {TM }}$ III and the acid phosphatase (AP) test using Seminal Fluid DISCHAPS ${ }^{\text {TM }}$.

Results: The ALS detected semen diluted until 5\% ( $/ / v$ ) fluid, whereas the AP assay was sensitive down to $0.5 \%$ $(\mathrm{V} / \mathrm{V})$. Non-blood-containing stains were visible under blue light except on dark-colored cloth. All semen-containing fluids including post-ejaculatory urine tested positive for AP and Sg. RSID ${ }^{T M}$-Semen was sensitive down to $0.5 \mathrm{~nL}$ of semen; did not cross-react with blood, saliva, and female urine; and successfully detected Sg on the majority of post-coital samples tested. Complete short tandem repeat (STR) profiles of the semen donors were generated for most samples incubated in the RSID ${ }^{\mathrm{TM}}$-Universal Buffer (UB). However, we report an extraction efficiency of 15\% for UB which can lead to partial profiles in already compromised samples.
\end{abstract}

Conclusion: We recommend the use of ALS in visualizing stains present on surfaces and the AP test on bloodstained materials. These presumptive tests should be followed by $\mathrm{RSID}^{\mathrm{TM}}$-Semen test to confirm the presence of semen prior to DNA profiling.

Keywords: Semen detection, Sexual assault, Semenogelin, Acid phosphatase test, Alternate light source, Short tandem repeat typing, Philippines

\section{Background}

Women and Child Protection Units (WCPUs) in Philippine government hospitals are mandated by the Department of Health (DOH) to administer to women and children victims of abuse (DOH Administrative Order 2013-0011). In 2017, WCPUs received 8002 reports of sexual abuse in women and children (Child Protection Network Annual Report 2017). Despite the high number of crimes, there are only three laboratories in the country that can perform forensic DNA analysis for sexual assault investigations-the DNA Analysis Laboratory at the Natural Sciences Research Institute, University of the Philippines Diliman, and the crime

\footnotetext{
* Correspondence: madeungria@up.edu.ph

${ }^{1}$ DNA Analysis Laboratory, Natural Sciences Research Institute, College of Science, University of the Philippines Diliman, Quezon City 1101, Philippines Full list of author information is available at the end of the article
}

laboratories of the Philippine National Police (PNP) and the National Bureau of Investigation (NBI). The absence of a law requiring the routine collection, proper storage, and testing of biological specimens (Sugue-Castillo 2009) contributes to the backlog of cases that mostly use testimonial evidence in courts of law, as well as the degradation of samples due to improper handling and exposure to warm and humid conditions prevalent in tropical regions.

Before DNA is extracted from specimens collected from a medico-legal examination or recovered from crime scenes, different methods for detecting semen and other body fluids are employed. Such screening tests, while determining the tissue source of the DNA, are usually relevant in supporting activity level propositions, for example, that sexual intercourse occurred between two persons (Taylor et al. 2018). As semen may be 
present in trace amounts (Hall and Ballantyne 2003), diluted, or commingled with other body fluids (Apostolov 2014), techniques employed should demonstrate high sensitivity and specificity. In addition, to successfully link the criminal activity to the identity of its perpetrator, the procedure should allow DNA extraction to be directly performed on the same materials tested for semen.

It is often useful to conduct a preliminary screening to narrow down possible locations of semen stains. An alternate light source (ALS) such as an ultraviolet (UV) lamp can be used in locating stains that are otherwise invisible or difficult to observe under normal lighting conditions. Different stains fluoresce under ALS (Santucci and Nelson 1999; Vandenberg and van Oorschot 2006) with optimum excitation at certain wavelengths. Semen is best detected under blue light $(\sim 450 \mathrm{~nm})$ viewed through orange barrier filter goggles (Vandenberg and van Oorschot 2006). A more specific test targets seminal acid phosphatase (AP), where a positive reaction gives a purple color (Greenfield and Sloan 2003). Results of ALS and AP tests are presumptive (Davies and Wilson 1974; Hooft and Van De Voorde 1990, 1994; Santucci and Nelson 1999; Greenfield and Sloan 2003; Vandenberg and van Oorschot 2006) and should be followed by a confirmatory test for semen.

Microscopic examinations for sperm cells using stains such as nuclear fast red and picroindigocarmine (Christmas tree stain) or hematoxylin and eosin (H\&E) (Paterson et al. 2006; Sanders et al. 2006) are standard confirmatory tests for semen but are not useful when the human source is azoospermic or when cells had already disintegrated. Since majority of child sexual abuse victims examined by Philippine WCPUs in a 4-year period (January 2002-March 2006) were reportedly negative for sperm (Maiquilla et al. 2011), an approach other than microscopy to confirm the presence of semen must be adopted for routine screening. One such test, the $\mathrm{RSID}^{\mathrm{TM}}{ }_{-}$Semen (Independent Forensics, IL, USA) detects human semenogelin (Sg), a protein abundantly expressed in semen (Sato et al. 2001; Lundwall et al. 2002), via immunochromatography. A sample suspected to contain semen is incubated in RSID $^{\mathrm{TM}}$-Universal Buffer (UB) (Independent Forensics 2011) then the resulting extract is deposited onto the sample well of the cassette. Two red lines on the cassette strip indicate a positive result while a single line means negative.

To contribute to recommendations for processing and analysis of sexual assault evidence in Philippine forensic laboratories, we evaluated the sensitivity and specificity of three procedures, namely the use of a blue $(450 \mathrm{~nm})$ ALS or the Mini BLUMAXX ${ }^{\mathrm{TM}}$ III (Sirchie ${ }^{\oplus}, \mathrm{NC}$, USA), an AP test kit or the Seminal Fluid DISCHAPS ${ }^{\mathrm{TM}}$ (Sirchie $^{\circ}$ NC, USA), and the Sg detection kit, RSID $^{\mathrm{TM}}$-Semen. We further assessed the extraction efficiency of RSID ${ }^{\mathrm{TM}}$-Universal Buffer and performed ALS and Sg tests on various post-coital samples prior to DNA extraction to evaluate the suitability of integrating the tests into a routine short tandem repeat (STR) DNA profiling workflow.

\section{Materials and methods Collection and storage of samples}

Five males, ages 19 to 26 years (designated as males 1 to 5), provided semen samples. One of the donors (male 5) also submitted a post-ejaculatory urine sample. A female volunteer who had no sexual contact for several weeks prior to sample collection provided saliva, peripheral blood, and urine samples. A male-female couple and male-male couple each provided five post-coital swabs (vaginal and anal swabs, respectively), two used condoms, and two pieces of stained cotton-polyester underwear worn for at least $1 \mathrm{~h}$ post-coitus by the receptive partner. Each specimen was obtained separately from a total of nine occasions of sexual intercourse. Reference blood samples were blotted onto individual $\mathrm{FTA}^{\mathrm{TM}}$ Classic cards (GE Healthcare, Little Chalfont, UK). Liquid specimens were maintained at $4{ }^{\circ} \mathrm{C}$ storage and processed within the day of collection. Post-coital samples were air-dried for at least $1 \mathrm{~h}$ before sealing in conical tubes or paper envelopes before transport to the laboratory. These were kept at room temperature until processing ( $0-72$ days).

\section{Sensitivity study}

For the ALS and AP tests, dilution series $(1 / 2,1 / 4,1 / 8,1 /$ $20,1 / 200,1 / 2000,1 / 20,000,1 / 200,000$, and $1 / 2,000,000)$ in phosphate-buffered saline (PBS) were prepared from the semen samples $(n=5)$. Each semen/PBS dilution was deposited onto $49-\mathrm{cm}^{2}$ cotton cloth in $150-\mu \mathrm{L}$ aliquots and then air-dried. These stains were photographed under normal lighting and through orange barrier filter goggles under the Mini BLUMAXX ${ }^{\mathrm{TM}}$ III LED illuminator. AP test using Seminal Fluid DISCHAPS ${ }^{\mathrm{TM}}$ was conducted on the same setups following manufacturer's protocol. This involved pressing a moistened filter paper on the cloth, mixing chemicals contained in an ampoule provided then treating the filter paper with the liquid from the ampoule. Positive results for semen appeared as purple coloration on the paper after $2 \mathrm{~min}$.

For the Sg test, two different stock extracts were prepared for the semen samples $(n=5)$ using UB to achieve a wide range of concentrations that overlap with the semen/PBS dilution series. For each sample, a 50- $\mu \mathrm{L}$ aliquot was deposited each onto two $400-\mathrm{mm}^{2}$ cotton cloths and air-dried. One cloth was incubated in $400 \mu \mathrm{L}$ UB for $2 \mathrm{~h}$. The resulting extract (stock A) was serially diluted $(1 / 2,1 / 4,1 / 8$, and $1 / 16)$ with UB. The other cloth was incubated in $1 \mathrm{~mL} \mathrm{UB}$ (stock $B$ ) and subsequently serially diluted $(1 / 10,1 / 100,1 / 1000,1 / 10,000$, and $1 / 100,000)$ with UB. Diluted semen samples were deposited in $100-\mu \mathrm{L}$ aliquots onto sample wells of $\mathrm{RSID}^{\mathrm{TM}}$-Semen cassettes. Positive and negative results were read after $10 \mathrm{~min}$. 
Table 1 lists the concentrations achieved for each preparation in percent volume/volume (\% v/v).

\section{Specificity and interference studies}

Neat semen and post-ejaculatory urine samples from male 5; neat saliva, urine, and peripheral blood samples from the female donor; and mixtures in equal proportions of components (mixture 1-peripheral blood, saliva, and female urine; mixture 2-peripheral blood, saliva, and postejaculatory male urine; mixture 3-semen, peripheral blood, saliva, and female urine; mixture 4-semen, peripheral blood, saliva, and post-ejaculatory male urine) were deposited in $150-\mu \mathrm{L}$ aliquots onto $49-\mathrm{cm}^{2}$ cotton-polyester cloth, air-dried, then subjected to ALS and AP tests as previously described. In addition, $100-\mu \mathrm{L}$ semen samples from male 5 were deposited onto $49-\mathrm{cm}^{2}$ fabric of different types namely cotton-polyester, rayon, silk, satin, wool, and denim of three different shades; air-dried; and visualized using ALS. For the Sg test, $50 \mu \mathrm{L}$ each of the same neat and mixed samples were deposited onto separate 400- $\mathrm{mm}^{2}$ cotton-polyester cloth, air-dried, and submerged in $1 \mathrm{~mL} \mathrm{UB}$ for $2 \mathrm{~h}$. Aliquots of $100-\mu \mathrm{L}$ extract were deposited on the cassettes.

\section{Extraction efficiency of RSID ${ }^{\mathrm{TM}}$-Universal Buffer based on DNA recovery}

Each semen sample from five males was deposited in 50$\mu \mathrm{L}$ aliquots onto four separate $49-\mathrm{mm}^{2}$ cuttings of cottonpolyester cloth and dried in the dark at room temperature for about $48 \mathrm{~h}$. Each cutting was processed according to one of four extraction procedures: (1) DNA extraction of the stain using phenol-chloroform-isoamyl procedure (organic extraction); (2) 2-h incubation in $300 \mu \mathrm{L} \mathrm{UB}$ followed by organic extraction; (3) DNA extraction of the stain using QIAamp DNA Micro kit (QIAGEN, Hilden, Germany) procedure (silica-based extraction); and (4) 2-h incubation in $300 \mu \mathrm{L}$ UB followed by silica-based extraction. The unincubated cuttings (numbers 1 and 3) and a $100-\mu \mathrm{L}$ aliquot of each UB extract (numbers 2 and 4) were used as starting materials for DNA extraction. DNA quantitation was carried out with the $\mathrm{AB}^{\circ} 7500$ real-time polymerase chain reaction (PCR) machine (Thermo Fisher Scientific, MA, USA) using the Plexor HY Human DNA Quantitation Kit (Promega Corporation, WI, USA). DNA was amplified using two STR multiplex systems, namely PowerPlex $^{\circ} 21$ and PowerPlex ${ }^{\circ}$ Y23 Systems (Promega Corporation, WI, USA), in reduced volume $(10 \mu \mathrm{L})$ reactions containing 0.5-ng DNA template. Low-concentration DNA was amplified in full volume $(25 \mu \mathrm{L})$ to enable the addition of the 0.5-ng template. PCR amplification was performed using the $\mathrm{AB}$ GeneAmp 9700 (Thermo Fisher Scientific, MA, USA). Amplified fragments were separated and detected with the $A B^{\circ} 310$ and 3500 Genetic Analyzers (Thermo Fisher Scientific, MA, USA) and analyzed with GeneMapper $I D-X$ software version 1.2 (Thermo Fisher Scientific, MA, USA) following prescribed protocols.

DNA yields were compared between buffer incubated and non-incubated samples. Since only one-third of the buffer extract $(100-\mu \mathrm{L}$ aliquot of $300 \mu \mathrm{L})$ was used for DNA extraction, UB extraction efficiency was estimated

Table 1 Sensitivity of three semen detection tests. Positive or negative scores are shown for each donor (males 1-5)

\begin{tabular}{|c|c|c|c|c|c|c|c|c|c|c|c|c|c|c|c|}
\hline \multirow{2}{*}{$\begin{array}{l}\text { Concentration } \\
\text { of semen }(\% v / v)^{a}\end{array}$} & \multicolumn{5}{|l|}{ ALS } & \multicolumn{5}{|l|}{ AP } & \multicolumn{5}{|l|}{$\mathrm{Sg}$} \\
\hline & 1 & 2 & 3 & 4 & 5 & 1 & 2 & 3 & 4 & 5 & 1 & 2 & 3 & 4 & 5 \\
\hline 100 & + & + & + & + & + & + & + & + & + & + & n.d. & n.d. & n.d. & n.d. & n.d. \\
\hline 50 & + & + & + & + & + & + & + & + & + & + & n.d. & n.d. & n.d. & n.d. & n.d. \\
\hline 25 & + & + & + & + & + & + & + & + & + & + & n.d. & n.d. & n.d. & n.d. & n.d. \\
\hline 12.5 & + & + & + & + & + & + & + & + & + & + & + & + & + & + & + \\
\hline 6.25 & n.d. & n.d. & n.d. & n.d. & n.d. & n.d. & n.d. & n.d. & n.d. & n.d. & + & + & + & + & + \\
\hline 5 & + & - & - & - & - & + & - & + & - & + & + & + & + & + & + \\
\hline 3.125 & n.d. & n.d. & n.d. & n.d. & n.d. & n.d. & n.d. & n.d. & n.d. & n.d. & + & + & + & + & + \\
\hline 1.5625 & n.d. & n.d. & n.d. & n.d. & n.d. & n.d. & n.d. & n.d. & n.d. & n.d. & + & + & + & + & + \\
\hline 0.8929 & n.d. & n.d. & n.d. & n.d. & n.d. & n.d. & n.d. & n.d. & n.d. & n.d. & + & + & + & + & + \\
\hline 0.5 & - & - & - & - & - & - & - & - & - & + & + & + & + & + & + \\
\hline 0.05 & - & - & - & - & - & - & - & - & - & - & + & + & + & + & + \\
\hline 0.005 & - & - & - & - & - & - & - & - & - & - & + & + & + & + & + \\
\hline 0.0005 & - & - & - & - & - & - & - & - & - & - & + & - & + & - & - \\
\hline 0.00005 & - & - & - & - & - & - & - & - & - & - & - & - & - & - & - \\
\hline $0^{b}$ & - & - & - & - & - & - & - & - & - & - & - & - & - & - & - \\
\hline
\end{tabular}

n.d. not done (as different series of diluted semen were prepared separately for ALS/AP and Sg tests, not all concentrations listed were applicable to the tests) asemen lost due to $<100 \%$ efficiency of UB extraction was not accounted for in the computation

${ }^{\mathrm{b}}$ This represents the negative control where PBS was used for the ALS/AP tests and UB for the Sg test 
as the proportion of three times the DNA yield of a buffer incubated stain over the DNA yield of its corresponding non-incubated stain. Values were averaged across all samples. Percent allele recovery was calculated as the proportion of the observed number of alleles in a sample to the total number of expected alleles in the reference DNA profile of its donor.

\section{Semen detection and DNA typing of post-coital samples}

Condoms and underwear were inspected and photographed under normal lighting and through orange barrier filter goggles under blue light. Small cuttings $\left(\sim 100 \mathrm{~mm}^{2}\right)$ were obtained from areas on the underwear where the presence of stain was observed. For the female underwear, five cuttings were obtained from each piece, while two and eight cuttings each were sampled, respectively, from the first and second collections from the male receptive partner. Two cotton swabs moistened with sterile distilled water were rubbed on the external surface and another two on the internal surface of condoms. Cotton battings from the vaginal/anal and condom swabs and underwear cuttings were individually submerged in $400 \mu \mathrm{L}$ UB for $2 \mathrm{~h}$ in room temperature. Aliquots of $10 \mu \mathrm{L}$ were obtained from each extract and diluted with $90 \mu \mathrm{L}$ of UB. The resulting $100-\mu \mathrm{L}$ diluted extracts were each deposited onto pre-labeled cassettes. Sg results were scored after $10 \mathrm{~min}$.

DNA was extracted using two procedures, organic extraction and the silica-based QIAamp DNA Micro following the manufacturer's protocol. In both methods, $100 \mu \mathrm{L}$ of each UB extract was used as starting material. STR DNA typing proceeded as described in the previous section. For the resulting electropherograms (epgs), percent recovery was calculated for each contributor as the proportion of his/her own unshared alleles observed over the total number of unshared alleles in his/her reference DNA profile.

\section{Results}

\section{Sensitivity study}

Results of the three tests on decreasing concentrations of semen from five males are presented in Table 1. In both the ALS and AP tests, positive results were observed consistently until $12.5 \%(v / v)$ semen. The ALS can still detect the stain down to $5 \%(v / v)$ of one semen sample, whereas the AP test until $0.5 \%(v / v)$ of one sample. Additional file 1: Figure S1-S2 shows representative photographs of the sensitivity results for ALS and AP tests. In the Sg test, positive results were observed in all five samples until $0.005 \%(v / v)$ of the extract or a total input volume of $5 \mathrm{~nL}$ semen. Two of five samples further tested positive at $0.0005 \%(\mathrm{v} / \mathrm{v})$ (total semen input volume $0.5 \mathrm{~nL}$ ). The band along the test line decreased in intensity for semen concentrations starting at $0.5 \%(v / v)(500 \mathrm{~nL})$ semen and higher indicating a high-dose hook effect (Additional file 1: Figure S3). The concentrations are conservative estimates as semen lost due to $<100 \%$ extraction by UB was not accounted for, albeit an estimate of extraction efficiency based on DNA quantitation is reported below.

\section{Specificity and interference studies}

Table 2 summarizes the results of the three tests on semen, non-semen fluids, and mixtures. Specificities of AP and Sg tests were concordant in showing positive results only for semen-containing and post-ejaculatory urine-stained material. The ALS caused semen and male and female urine to fluoresce intensely, while the saliva stain was only weakly visible. The urine stain can be distinguished by its scattered distribution and coarse edges, while the semen stain was more localized with a smooth outline. None of the blood-containing stains fluoresced (Fig. 1).

With the ALS test on different fabric types, semen was most conspicuous on the cotton-polyester cloth, with the stain appearing on a wide area. The stain on rayon was intensely visible but covered a smaller area, while the stain on silk had a weak contrast. Even weaker contrast was exhibited by the stain on satin where the background also fluoresced under the lighting. Stains were not visible on darkly colored wool and denim (Additional file 1: Figure S4).

\section{Extraction efficiency of RSID ${ }^{\mathrm{TM}}$-Universal Buffer and allele recovery in UB-extracted samples}

An average of $15 \%$ recovery of semen DNA from cottonpolyester material was observed when UB was used (Table 3). The five semen samples extracted using four procedures, amplified using two multiplex systems, and analyzed using two capillary electrophoresis (CE) systems resulted in 80 epgs. All autosomal and Y-chromosomal amplifications on non-incubated samples resulted in full allele recovery. Seven of the 80 epgs, all from males 2 and 3 , and from UB incubated samples, showed partial recovery. Three autosomal epgs had recoveries from $64 \%$ to

Table 2 Specificity of three semen detection tests

\begin{tabular}{llcr}
\hline Specimen tested & ALS & AP & Sg \\
\hline Semen & + & + & + \\
Peripheral blood & - & - & - \\
Saliva & + (weak $)$ & - & - \\
Female urine & + & - & - \\
Post-ejaculatory male urine & + & + & + \\
Mixture 1 & - & - & - \\
Mixture 2 & - & + & + \\
Mixture 3 & - & + & + \\
Mixture 4 & - & + & + \\
\hline
\end{tabular}

Mixture 1: peripheral blood, saliva, and female urine (1:1:1)

Mixture 2: peripheral blood, saliva, and post-ejaculatory male urine (1:1:1)

Mixture 3: semen, peripheral blood, saliva, and female urine (1:1:1:1)

Mixture 4: semen, peripheral blood, saliva, and post-ejaculatory male urine $(1: 1: 1: 1)$ 


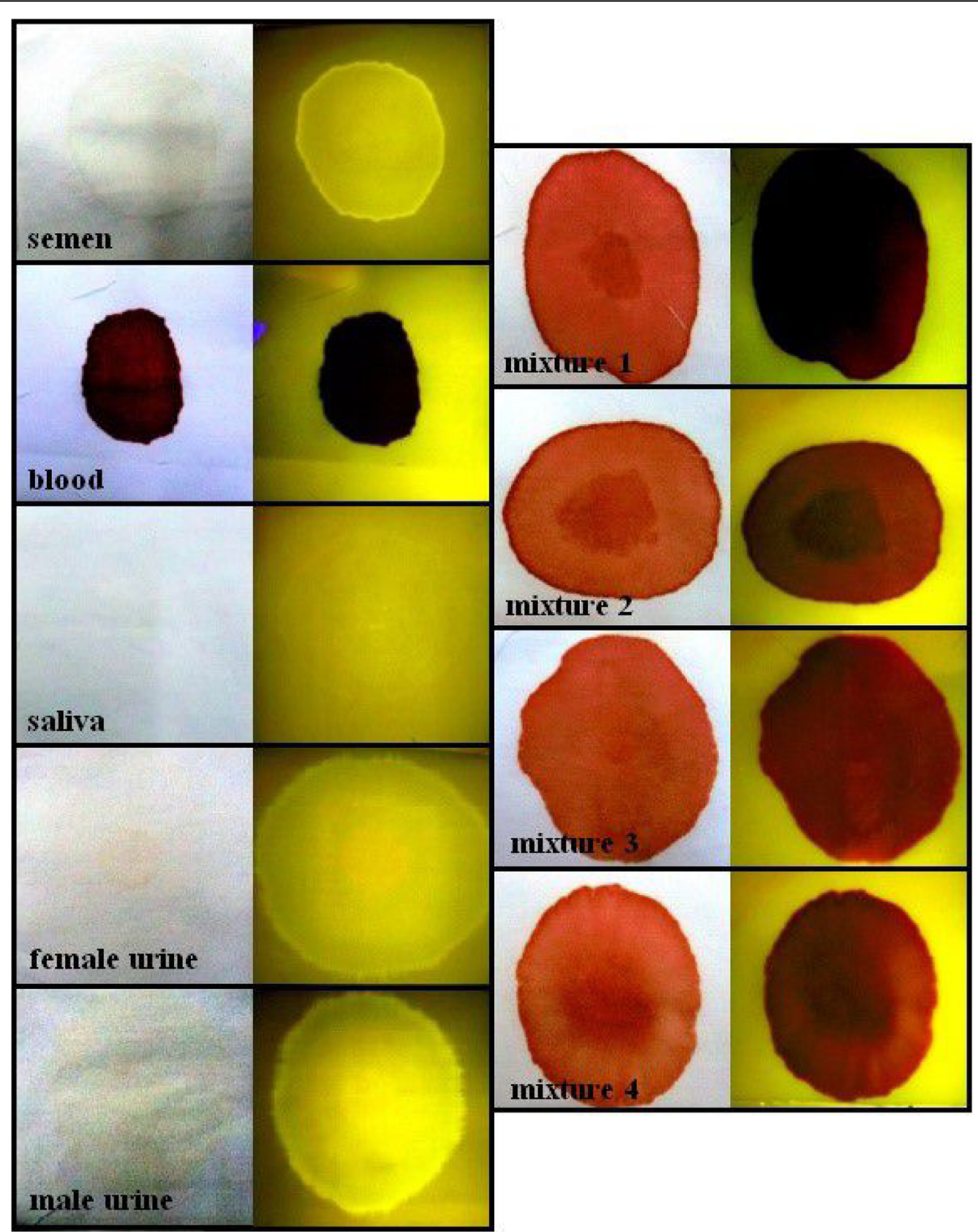

Fig. 1 Specificity and interference of Mini BLUMAXX ${ }^{\mathrm{TM}}$ III. Individual figure for each setup shows the stain on cotton-polyester under normal lighting (left) and blue light viewed through orange barrier filter goggles (right). Mixture 1: peripheral blood, saliva, and female urine (1:1:1); Mixture 2: peripheral blood, saliva, and post-ejaculatory male urine (1:1:1); Mixture 3: semen, peripheral blood, saliva, and female urine (1:1:1:1); Mixture 4: semen, peripheral blood, saliva, and post-ejaculatory male urine (1:1:1:1)

97\%, while four Y-chromosomal epgs showed recoveries ranging from $35 \%$ to $74 \%$.

\section{Semen detection and DNA typing of post-coital samples} We proceeded only with the ALS for presumptive testing of post-coital stains and condoms due to its ability to make stains visible without moistened contact on the sample. Figure 2 presents the results of semen tests on post-coital samples. The blue light successfully located semen on underwear and in condoms. Sg-positive results were observed in 39 out of 46 samples tested (85\%). The vaginal swabs had yellowish-brown coloration on the cotton batting, whereas anal swabs were dark brown due to traces of fecal material. All five vaginal swabs were $\mathrm{Sg}$ positive, while two out of the five anal swabs were Sg negative. Notably, three anal swabs developed conspicuous mold growth after being stored at room temperature for several days (55-69 days) before processing. Stains on female underwear were visible even under normal lighting as yellowish-brown areas on the cloth. The stains were fluorescent in the dark when viewed through orange goggles under blue light (Additional file 1: Figure S5-A). No stain was initially visible on one underwear from the male-male couple, but using the ALS, a small 
Table 3 Extraction efficiency of RSID ${ }^{T M}$-Universal Buffer based on DNA quantitation

\begin{tabular}{llll}
\hline Sample code & Non-incubated (ng) & $\begin{array}{l}\text { RSID }^{\mathrm{TM}} \text {-UB } \\
\text { incubated (ng) }\end{array}$ & $\begin{array}{l}\text { Extraction } \\
\text { efficiency }^{\mathrm{b}}\end{array}$ \\
\hline 1_Organic & 664.20 & 33.86 & 0.15 \\
2_Organic & 745.50 & 20.46 & 0.08 \\
3_Organic & 139.40 & 2.99 & 0.06 \\
4_Organic & 713.55 & 20.40 & 0.09 \\
5_Organic & $1,197.00$ & 75.21 & 0.19 \\
1_Silica-based & 400.00 & 17.93 & 0.13 \\
2_Silica-based & 118.80 & 10.53 & 0.27 \\
3_Silica-based & 31.35 & 0.84 & 0.08 \\
4_Silica-based & 108.30 & 13.02 & 0.36 \\
5_Silica-based & 493.50 & 13.23 & 0.08 \\
& & Average & $0.15( \pm 0.10)$
\end{tabular}

${ }^{\mathrm{a}}$ Donor_DNA extraction procedure

${ }^{b}$ Estimated as the proportion of three times the DNA yield of RSID ${ }^{T M}$-Universal Buffer incubated stain over the DNA yield of corresponding non-incubated stain

fluorescent spot was observed. The second collection had visible semen and fecal stains. The stains appeared larger and more noticeable using the ALS. Cuttings for subsequent $\mathrm{Sg}$ tests were obtained from these fluorescent areas on the underwear. Only one of the 20 stain cutting samples tested negative for Sg. All post-coital condoms fluoresced in the dark using the ALS when viewed through orange goggles (Additional file 1: Figure S5-B). Internal condom swabs were positive for Sg, whereas external swabs were negative to very weakly positive.

Using two extraction procedures, two CE instruments, and typing for the autosomal and Y-chromosomal STRs resulted in 360 epgs. Two-person autosomal mixtures were apparent for most samples including vaginal/anal swabs, underwear stains, and a few condom swabs. Single Y-chromosomal profiles were evident in male-female samples (Additional file 1: Figure S6) while haplotype mixtures were revealed in male-male samples (Additional file 1: Figure S7). Figure 2 shows percent allele recovery across samples, amplifications, and instruments. Recovery of autosomal and Y-chromosomal alleles from male contributors was comparable within samples due to the amount of human DNA template $(0.5 \mathrm{ng})$ used in both PP21 and PPY23 reactions. However, there were a few samples which showed partial autosomal profiles of the semen contributor but revealed full Y-STR profiles (e.g., MM_Stn2e run in $\mathrm{AB}^{\circ}$ 310). Variable recovery of unshared alleles between penetrative and receptive partner components was observed across samples. Almost all vaginal swabs except one showed full recovery of contributor alleles, whereas most anal swabs showed partial profiles. Male-male samples in general showed greater loss of alleles, but these were more frequent in the receptive partner unlike in male-female samples where drop-outs more often occurred in the semen contributor. For samples excluding condom swabs, the majority resulted in full allele recovery of the semen component at 169 out of 232 epgs (72\%). All Sg-negative samples resulted in partial profiles of the penetrative partner with exceptions in one anal swab showing complete recovery of the semen contributor depending on the extraction method and CE instrument employed (Fig. 3). Generally, alleles were better recovered in samples run using $\mathrm{AB}^{\circ} 3500$.

\section{Discussion}

Recommendations with defined parameters that are based on validated protocols and casework experience are needed to advance the country's capacity for sexual assault investigations. Our previous work addressed some aspects of DNA testing for sexual assault cases particularly DNA extraction procedures (Rodriguez et al. 2017) and probabilistic methods to interpret mixtures (Rodriguez et al. 2019) considering the dynamics of sexual assault investigations in the Philippines. In this study, we evaluated the sensitivity and specificity of presumptive and confirmatory tests for semen and assessed whether these could be incorporated into standard procedures for STR DNA typing.

We have demonstrated RSID $^{\text {TM }}$-Semen to be specific and sensitive to semen. We prepared lower dilutions of semen than those in the developmental validation (Old et al. 2012) and observed a lower limit of detection for the Sg test $(0.5 \mathrm{~nL}$ vs. $2.5 \mathrm{~nL})$ as well as a positive reaction to post-ejaculatory urine. Another advantage of the Sg test is that the buffer extract can be used directly to extract the DNA. This allows the semen test to be incorporated into the DNA typing workflow while maximizing the information obtained from a single sample. In the majority of the samples tested, the complete profile of the semen donor was generated, which as applied in casework means comparison with a reference profile can generate a strong support for the person-of-interest's contribution or noncontribution to the evidence.

A possible drawback of using the RSID ${ }^{\mathrm{TM}}$-Universal Buffer on post-coital samples is its low extraction efficiency. While the majority of UB-extracted specimens had full recovery of alleles from semen, this may not be true for actual case samples in severely compromised states. Semen samples collected from two males showed partial profiles after UB extraction. This could be due to natural variation in semen quality among men ( $\mathrm{Li}$ et al. 2009; Molina et al. 2010; Singh et al. 2010) and adding a UB extraction step led to loss of DNA. Several factors influence DNA recovery which include sample type and condition (Rodriguez et al. 2017), time and activities since intercourse (Hall and Ballantyne 2003; Cerdas et al. 2016), semen quality of the source (Ballantyne 2012), extraction procedures (Vuichard et al. 


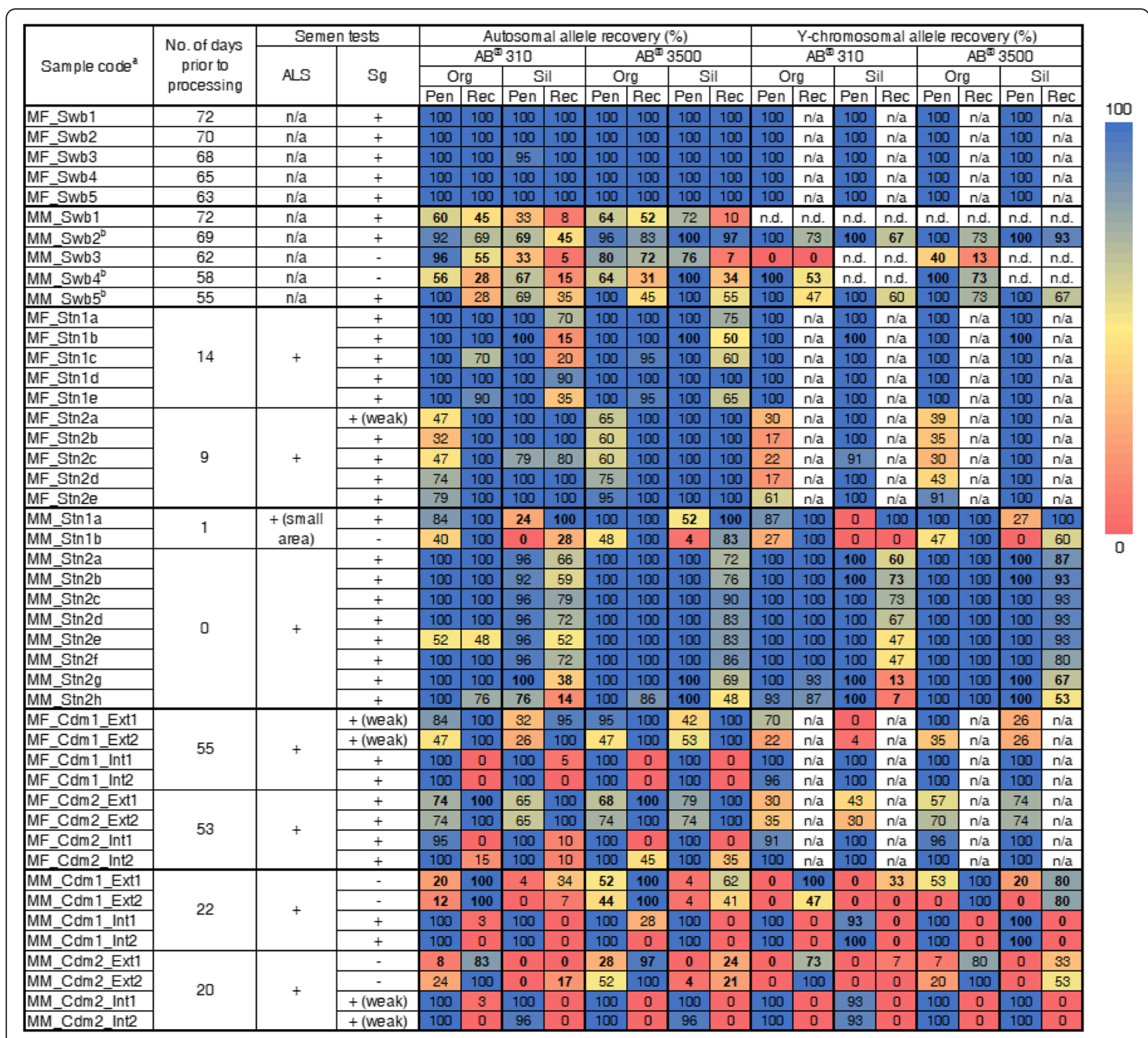

Fig. 2 Semen detection and recovery of unshared alleles among contributor components in post-coital samples. Superscript a indicates MF, male-female; MM, male-male; Swb, swab; Stn, stain; Cdm, condom; Ext, external swab; Int. internal swab. Superscript b indicates with visible mold growth. Org, organic extraction; Sil, silica-based extraction; Pen, penetrative partner; Rec, receptive partner; n/a, not applicable; and n.d, not done (the DNA extract was deficient in amount such that not enough template was left for Y-chromosomal typing). Values in boldface indicate samples amplified in full volume $(25 \mu \mathrm{L})$ reaction to accommodate 5 -ng DNA template mass. The rest were amplified in reduced volume (10 $\mu \mathrm{L})$

2011; Garvin et al. 2012; Rodriguez et al. 2017), multiplex systems (Ferreira-Silva et al. 2018), PCR and CE conditions (Hall and Ballantyne 2003; Westen et al. 2009), among others. Along the entire process, the forensic DNA analyst should therefore implement measures to maximize recovery of alleles to enable interpretation, for example using a method that enhances isolation of semen DNA. It is also for this reason that victims of sexual assault are advised not to wash or bathe following contact and to undergo medico-legal examination in the soonest possible time. Direct DNA extraction without using UB would arguably improve recovery of alleles. Therefore, upon assessment of specimen quality and being informed of the time of collection since contact as well as the extent of the victim's narrative regarding the incident, the analyst should decide whether to perform the Sg test on the samples.

Two mold-infested anal swab samples tested negative for Sg. However, we cannot absolutely determine whether this was due to fungal growth since one moldinfested anal swab was Sg positive. Despite this, partial to full profiles of the semen source were obtained from these Sg-negative samples, consistent with previous studies reporting the recovery of autosomal and Y-STR 

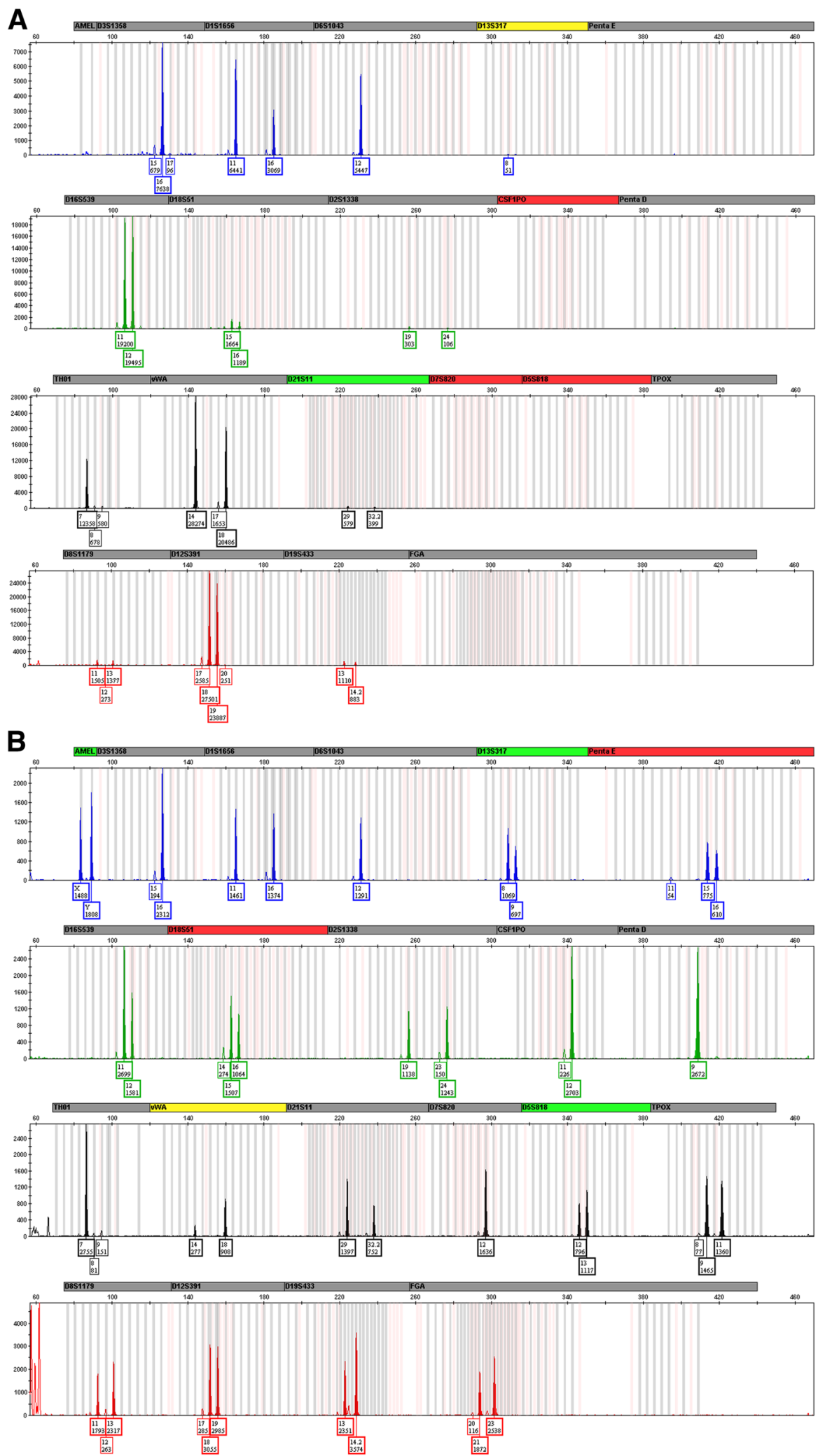

Fig. 3 Representative electropherograms for an Sg-negative and mold-infested male-male anal swab (MM_Swb4) showing partial autosomal allele recovery of the semen contributor after organic extraction (a) and full recovery of semen-derived alleles using the silica-based procedure (b). Both samples were run in $\mathrm{AB}^{\oplus}$ 3500. Semen contributor alleles are highlighted 
alleles from $\mathrm{Sg}$ and prostate-specific antigen (PSA) negative post-coital swabs (Benschop et al. 2010; Martínez et al. 2015). Overall, these suggest that STR DNA typing is more sensitive than Sg testing and that DNA profiles of the semen source can still be obtained despite a negative semen test but with the risk of only recovering partial profiles. This has implications for DNA typing not only of samples with trace amounts of semen but also for rape cases in which the assailant failed to ejaculate (Soares-Vieira et al. 2007).

For presumptive testing, we have shown that the 450-nm light source can easily locate stains present on surfaces such as latex and light-colored cloth. This is preferred over the AP test which involved moistened contact with the material. However, blue light failed to locate semen in the presence of blood; thus, the need for an AP test if a bloodstained material is suspected to contain semen. Blue light viewed through orange filter also has limitations on certain types of fabric; thus, the utility of other wavelengths of light and various barrier filters merit further evaluation.

Based on the results of this study, we propose a workflow for Philippine forensic DNA laboratories in detecting semen on various sexual assault samples (Fig. 4). For samples present on surfaces, visual inspection under normal lighting then under blue light is recommended to narrow down the area where stains are likely located. For blood stains suspected to contain semen, parts of the stain should be tested for AP to determine areas which should be cut and incubated in UB. For condoms, swabbing should be done along the outer and inner surfaces of the latex to collect cells from the receptive person's epithelium and the semen, respectively. To confirm the presence of semen, cuttings and swabs may be tested with RSID $^{\mathrm{TM}}$-Semen if this will not further compromise DNA recovery. If initially, the Sg test is negative, dilution of the swab extract, e.g., 1/ 20 dilution, with UB can counteract possible high-dose hook effect (Old et al. 2012). STR DNA typing may proceed despite a negative Sg result, but this is likely to result in partial recovery. However, if multiple swabs or cuttings were tested, DNA profiling may proceed only on UB extracts which showed the strongest positive signals. For a discussion on the use of autosomal and Y-chromosomal DNA typing on samples with a mixture of contributors, the reader is directed to the work of Rodriguez et al. (2017).

Another cause of failed detection is degradation by biological and/or chemical means. The results from the anal swabs that resulted in the growth of molds after prolonged storage at room temperature indicate the need for such samples to be processed immediately, or if not possible, to be kept at cold conditions. This is particularly important in tropical regions such as the Philippines where the warm and humid climate for much of the year can pose a problem in sample storage. Recommendations in this paper also apply to victims of sexual violence who are advised to undergo medico-legal examination within the soonest possible time and to avoid washing or bathing prior to sample collection.

\section{Conclusions}

The ALS, AP, and Sg tests are generally suitable in detecting semen from biological specimens. Procedures do not require sophisticated equipment nor advanced training for the personnel. Using Mini BLUMAXX ${ }^{\mathrm{TM}}$ III allows straightforward visualization of stains and used condoms, while the Seminal Fluid DISCHAPS ${ }^{\mathrm{TM}}$ can be used as presumptive screening for blood-stained material suspected to contain semen. The RSID ${ }^{\mathrm{TM}}$-Semen test is sensitive and specific to semen and involves simple steps which could be integrated into standard DNA profiling procedures. We emphasize however that the condition of the sample before DNA extraction remains a critical factor to the success of both semen detection and DNA analysis.

Forensic DNA laboratories with limited resources experiencing a huge backlog of sexual assault cases will benefit from adoption of these procedures to form a strategic plan for analysis, e.g., preliminary screening of samples, which samples should be processed first, and those which should be stored in cold storage. This work has

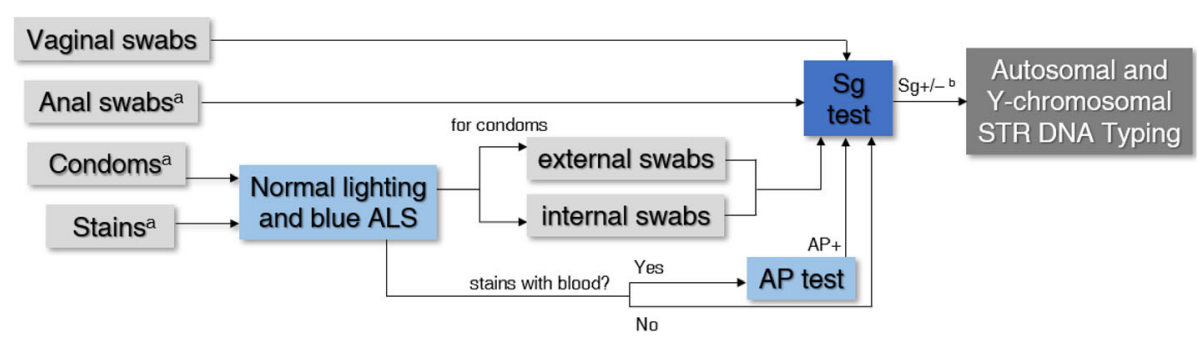

Fig. 4 A proposed workflow for semen detection in sexual assault samples. Light and dark blue shapes indicate presumptive and confirmatory tests, respectively. Superscript a indicates samples with fecal material should be processed immediately or otherwise kept in cold storage. Superscript $b$ indicates if multiple samples from a case were tested, and only those with the strongest positive signals may proceed to DNA typing 
demonstrated the usefulness of defined DNA protocols for different materials and conditions that are encountered during sexual investigations in the countries like the Philippines characterized by prolonged storage of biological samples at ambient temperatures, and limited human as well as testing resources for the immediate conduct of DNA tests on samples during forensic investigations. These methods can be adopted by other countries facing similar challenges in handling and processing of sexual assault evidence in their own local jurisdictions.

\section{Additional file}

Additional file 1: Fig. S1. Representative photographs showing sensitivity of Mini BLUMAXX ${ }^{T M}$ III. Figures are concentrations in $\% \mathrm{~V} / \mathrm{V}$. Fig. S2. Representative photographs showing sensitivity of Seminal Fluid DISCHAPS ${ }^{\text {TM }}$. Figures are concentrations in \% V/v. Fig. S3. Representative photographs showing sensitivity of RSID ${ }^{\text {TM }}$-Semen ${ }^{\text {TM }}$. Figures are concentrations in \% V/v. Fig. S4. Effect of various fabric types on semen stain visualization by Mini BLUMAXX ${ }^{T M}$ III. Fig. S5. Visualization of representative specimens of post-coital underwear stain (A) and condom (B) using Mini BLUMAXX'M III. Fig. S6. Representative electropherogram showing a Y-chromosomal profile from a vaginal swab obtained from a male-female pair. Fig. S7. Representative electropherogram showing a two-person Y-chromosomal haplotype mixture from an underwear stain obtained from a male-male pair. (PDF $2600 \mathrm{~kb}$ )

\section{Abbreviations}

ALS: Alternate light source; AP: Acid phosphatase; CE: Capillary electrophoresis; epg: Electropherogram; H\&E: Hematoxylin and eosin; NBI: National Bureau of Investigation; PBS: Phosphate buffered saline; PCR: Polymerase chain reaction; PNP: Philippine National Police; Sg: Semenogelin; STR: Short tandem repeat; UB: Universal Buffer; WCPUs: Women and Child Protection Units

\section{Acknowledgements}

The kits used in this study were generously provided by the Independent Forensics and Sirchie at reduced costs. We thank our colleagues in the University of the Philippines Diliman Natural Sciences Research Institute DNA Analysis Laboratory (UPD-NSRI DAL) for the technical assistance: Dame Loveliness T. Apaga, Miriam Ruth M. Dalet, Maria Lourdes D. Honrado, Minerva S. Sagum, and Jazelyn M. Salvador. We are also grateful to Dr. Bernadette J. Madrid and Dr. Merle P. Tan of the Philippine General Hospital - Child Protection Unit (PGH CPU) for the interesting discussions. Lastly, we thank our volunteers who kindly provided their samples for this study.

\section{Authors' contributions}

JJRBR collected the samples, designed and performed the experiments, generated and analyzed the data, and wrote and revised drafts of the manuscript. GCC collected the samples and contributed to writing the manuscript. RPL provided guidance to JJRBR and contributed to writing the manuscript. MCADU conceived the study, provided guidance to JJRBR, and contributed to writing and revising the manuscript. All authors contributed to the study design and had full approval of the submitted version.

\section{Funding}

This study was funded by the University of the Philippines System - Office of the Vice President for Academic Affairs (UP OVPAA) under a Creative Research Grant for MCADU and by the Commission on Higher Education (CHED) Thesis Grant for JJRBR.

\section{Availability of data and materials}

Most data generated or analyzed during this study are included in this published article and its additional file. Other data analyzed during the current study are available from the corresponding author by request.

\section{Ethics approval and consent to participate}

Ethical clearance was issued by the University of the Philippines Manila Research Ethics Board (UPMREB Code: 2012-321-01). All sample donors provided written informed consent to participate.

\section{Consent for publication}

Not applicable.

\section{Competing interests}

The authors declare that they have no competing interests.

\section{Author details}

${ }^{1}$ DNA Analysis Laboratory, Natural Sciences Research Institute, College of Science, University of the Philippines Diliman, Quezon City 1101, Philippines. ${ }^{2}$ Genetics and Molecular Biology Division, Institute of Biological Sciences, College of Arts and Sciences, University of the Philippines Los Baños, Laguna 4031, Philippines.

Received: 5 February 2019 Accepted: 14 July 2019

Published online: 02 August 2019

\section{References}

Apostolov A (2014) Differentiation of mixed biological traces in sexual assaults using DNA fragment analysis. Biotechnol Biotechnol Equip 28(2): 301-305

Ballantyne J (2012) DNA profiling of the semen donor in extended interval postcoital samples. (241299). Washington DC: NCJRS. https://www.ncjrs.gov/ pdffiles1/nij/grants/241299.pdf/. Accessed 28 Aug 2018.

Benschop CC, Wiesbosch DC, Kloosterman AD, Sijen T (2010) Post-coital vaginal sampling with nylon flocked swabs improves DNA typing. Forensic Sci Int Genet 4:115-121

Cerdas L, Herrera F, Arrieta G, Morelli C, Álvarez K, Gómez A (2016) Menstrual cycle phase at the time of rape does not affect recovery of semen or amplification of STR profiles of a suspect in vaginal swabs. Forensic Sci Int Genet 259:36-40

Child Protection Network (2017) Annual Report. https://www. childprotectionnetwork.org/wp-content/uploads/2019/03/CPN-AnnualReport-2017.pdf/. Accessed 15 June 2019.

Davies A, Wilson E (1974) The persistence of seminal constituents in the human vagina. Forensic Sci 3(1):45-55

Ferreira-Silva B, Fonseca-Cardoso M, Porto MJ, Magalhães T, Cainé L (2018) A comparison among three multiplex Y-STR profiling kits for sexual assault cases. J Forensic Sci 63(6):1836-1840

Garvin AM, Fisher A, Schnee-Griese J, Jelinski A, Bottinelli M, Soldati G, Tubio M, Castella V, Monney N, Malik N, Madrid M (2012) Isolating DNA from sexual assault cases: a comparison of standard methods with a nuclease-based approach. Investig Genet 3:25

Greenfield B, Sloan MA (2003) Identification of biological fluids and stains. In: James SH, Nordby JJ (eds) Forensic science: an introduction to scientific and investigative techniques. CRC Press, Boca Raton

Hall A, Ballantyne J (2003) Novel Y-STR typing strategies reveal the genetic profile of the semen donor in extended interval post-coital cervicovaginal samples. Forensic Sci Int 136:58-72

Hooft PJ, Van De Voorde HP (1990) The zinc test as an alternative for acid phosphatase spot tests in the primary identification of seminal traces. Forensic Sci Int 47:269-275

Hooft PJ, Van De Voorde HP (1994) Interference of body products, food and products from daily life with the modified zinc test and the acid phosphatase test. Forensic Sci Int 66(3):187-196

Independent Forensics (2011) IFI Developmental Validation of RSID ${ }^{\text {TM }}$-Universal Buffer. https://ifi-test.com/documents/UBValid.pdf/. Accessed 10 July 2016.

Li Y, Lin H, Ma M, Li L, Cai M, Zhou N, Han X, Bao H, Huang L, Zhu C, Li C, Yang H, Rao Z, Xiang Y, Cui Z, Ao L, Zhou Z, Xiong H, Cao J (2009) Semen quality of 1346 healthy men, results from the Chongqing area of southwest China. Hum Reprod 24(2):459-469

Lundwall A, Bjartell A, Olsson AY, Malm J (2002) Semenogelin I and II, the predominant human seminal plasma proteins, are also expressed in nongenital tissues. Mol Hum Reprod 8(9):805-810

Maiquilla SB, Salvador JM, Calacal GC, Sagum MS, Dalet MM, Delfin FC, Tabbada KA, . Franco SL, Perdigon HB, Madrid BJ, Tan MP, De Ungria MCA (2011) Y- 
STR DNA analysis of 154 female child sexual assault cases in the Philippines Int J Legal Med 125(6):817-824.

Martínez P, Santiago B, Alcalá B, Atienza I (2015) Semen searching when sperm is absent. Sci Justice 55:118-123

Molina RI, Martini AC, Tissera A, Olmedo J, Senestrari D, de Cuneo MF, Ruiz RD (2010) Semen quality and aging: analysis of 9,168 samples in Cordoba, Argentina. Arch Esp Urol 63(3):214-222

Old J, Schweers BA, Boonlayangoor PW, Fisher B, Miller KWP, Reich K (2012) Developmental Validation of $\mathrm{RSID}^{\mathrm{TM}}$-Semen: a lateral flow immunochromatographic strip test for the forensic detection of human semen. J Forensic Sci 57(2):489-499

Paterson SK, Jensen CG, Vintiner SK, McGlashan SR (2006) Immunohistochemical staining as a potential method for the identification of vaginal epithelial cells in forensic casework. J Forensic Sci 51:1138-1143

Rodriguez JJRB, Bright JA, Salvador JM, Laude RP, De Ungria MCA (2019) Probabilistic approaches to interpreting two-person DNA mixtures from postcoital specimens. Forensic Sci Int. 300:157-163

Rodriguez JJRB, Calacal GC, Laude RP, De Ungria MCA (2017) Non-differential DNA extraction of post-coital samples submitted as evidence for investigating sexual assault cases in the Philippines. Philipp Sci Lett 10(1):14-21

Sanders CT, Sanchez N, Ballantyne J, Peterson DA (2006) Laser microdissection separation of pure spermatozoa from epithelial cells for short tandem repeat analysis. J Forensic Sci 51:748-757

Santucci KA, Nelson DG (1999) Wood's lamp utility in the identification of semen Pediatrics 104(6):1342-1345

Sato I, Yoshiike M, Yamasaki T, Yoshida K, Takano S, Mukai T, Iwamoto T (2001) A dot-blot-immunoassay for semen identification using a polyclonal antibody against semenogelin, a powerful seminal marker. Forensic Sci Int 122:27-34

Singh AK, Tiwari AK, Singh PB, Dwivedi US, Trivedi S, Singh SK, Agrawal NK, Deshpande SB (2010) Multivitamin and micronutrient treatment improves semen parameters of azoospermic patients with maturation arrest. Indian J Physiol Pharmacol 54(2):157-163

Soares-Vieira JA, Billerbeck AEC, Sadayo E, Iwamura M, Zampieri RA, Gattás GJF, Muñoz DR, Hallak J, Mendonca BB, Lucon AM (2007) Y-STRs in forensic medicine: DNA analysis in semen samples of azoospermic individuals. $J$ Forensic Sci 52(3):664-670

Suque-Castillo M (2009) Legal outcomes of sexually abused children evaluated at the Philippine General Hospital Child Protection Unit. Child Abuse Negl 33(3):193-202

Taylor D, Kokshoorn B, Biedermann A (2018) Evaluation of forensic genetics findings given activity level propositions: a review. Forensic Sci Int Genet 36:34-49

Vandenberg N, van Oorschot RA (2006) The use of Polilight in the detection of seminal fluid, saliva, and bloodstains and comparison with conventional chemical based screening tests. J. Forensic Sci 51:361-370

Vuichard S, Borer U, Bottinelli M, Christian C, Malik N, Meier V, Gehrig C, Sulzer A, Morerod M, Castella V (2011) Differential DNA extraction of challenging simulated sexual-assault samples: a Swiss collaborative study. Investig Genet 2:11

Westen AA, Nagel JHA, Benschop CCG, Weiler NEC, Jong BJD, Sijen T (2009) Higher capillary electrophoresis injection settings as an efficient approach to increase the sensitivity of STR typing. J Forensic Sci 54(3):591-598

\section{Publisher's Note}

Springer Nature remains neutral with regard to jurisdictional claims in published maps and institutional affiliations.

\section{Submit your manuscript to a SpringerOpen ${ }^{\circ}$ journal and benefit from:}

- Convenient online submission

- Rigorous peer review

- Open access: articles freely available online

- High visibility within the field

- Retaining the copyright to your article

Submit your next manuscript at $\boldsymbol{\nabla}$ springeropen.com 